\title{
ALGUNAS EXPERIENCIAS EXITOSAS EN LATINOAMÉRICA RELACIONADAS CON LA ESTANDARIZACIÓN CONTABLE*
}

\author{
ABEL MARÍA CANO MORALES"* \\ UNIVERSIDAD DE MEDELLÍN
}

Recibido/ Received/ Recebido: 25/04/2010 - Aceptado/ Accepted / Aprovado: 28/11/2010

\begin{abstract}
Resumen
Este trabajo presenta de manera panorámica los procesos que han seguido algunos países latinoamericanos, con el fin de estandarizar sus procesos e información contable. Es evidente el protagonismo en las últimas décadas de las Normas Internacionales de Información Financiera (NIIF) y de la Normas Internacionales de Contabilidad (NIC) a raíz de los acontecimientos económicos, políticos y comerciales experimentados en el mundo y la región. El documento insiste en anotar que existe una necesidad latente de establecer un sistema de información contable internacional que minimice las discrepancias surgidas entre las normas contables nacionales y las internacionales; y que a la vez sea adoptado como herramienta homogenizadora global de la información contable. Palabras clave: Estandarización, Información contable, Normas internacionales de información financiera, Normas internacionales de contabilidad, Sistema de información contable internacional.
\end{abstract}

\section{SOME SUCCESSFUL EXPERIENCES RELATED TO ACCOUNTING STANDARDIZATION IN LATIN-AMERICAN}

\begin{abstract}
This paper presents, in general, the processes that some Latin-American countries have followed, with the purpose of standardizing their accounting processes and information. It is obvious the leadership that International Financial Report Standard (IFRS) and Accounting International Standard (AIS) have had in the last decades, due to economic, political and commercial events experienced regional and globally. This document insists in pointing out that there is a latent need to establish an international accounting information system, which minimize the discrepancies presented among national and international accounting rules; which should be adopted as a global harmonization tool of accounting information.
\end{abstract}

Key words: Stardardization. Accountable information. International Financial Report Standard, Accounting International Standard, International accounting information system

Este trabajo es unos de los resultados parciales, que se entregan a la comunidad académica producto de la ejecución del proyecto de investigación intitulado Conformación del Banco de Experiencias Exitosas en la Aplicación de las Normas Internacionales de Información Financiera (NIIF/NIC): en los Países de MERCOSUR, Comunidad Andina, México y España", desarrollado por el profesor investigador, el cual está siendo financiado por la Universidad de Medellín con cofinanciación de 16 instituciones educativas internacionales.

* Contador Público Titulado, Especialista en Gerencia de Impuestos, Especialista en Derivados, Futuros, Stocks y Opciones de Anglia Ruskin University, Magister en Administración Universidad Autónoma de Bucaramanga, Magister en Finanzas Instituto Tecnológico de Estudios Superiores de Monterrey, Docente Investigador de la Universidad de Medellín, autor y coautor de cuatro libros de investigación, cuatro capítulos de libro y de 35 artículos de investigación, conferenciante nacional e internacional. 


\title{
EXPERIÊNCIAS LATINO-AMERICANAS RELACIONADAS COM A NORMALIZAÇÃO CONTÁVEL INTERNACIONAL
}

\begin{abstract}
Resumo
Neste artigoapresenta-se a generalidade dos processos desenvolvidos em alguns países latinoamericanos para padronizar os processos e a informaçãocontável. Nas últimas décadas, como resultado dos eventos econômicos, políticos e comerciais experimentados no mundo, as normas internacionais de informaçãofinanceira têm sido notícia de primeiro plano; portanto, se examinam de modo geral os processos de discussão e de posta em prática.Conclui-se que as NIIF/NIC são um sistema de comunicação confiável e acessível àsatuais relações econômicas complexas, cuja aplicação tem vantagens e desvantagens.
\end{abstract}

Palavras-chave: Padronizaçãocontável, informação contável, normas internacionais de informação financeira, normas internacionais de contabilidade.

Cano, A. (2010) Algunas experiencias exitosas en Latinoamérica relacionadas con la estandarización contable. En: Revista de la Facultad de Ciencias Económicas de la Universidad Militar Nueva Granada. rev.fac.cienc.econ, XVIII (2).

JEL: M40, M41, M54.

\section{Introducción}

En este acápite se presentaran las principales experiencias de adopción, adaptación o de armonización de las Normas Internacionales de Contabilidad, que han tenido algunos de los princiales países latinoamericanos, tales como Argentina, Brasil, Bolivia, Chile, Costa Rica, Ecuador, Perú, y Venezuela, con el fin de asimilarlos como experiencias exitosas para la dinámica globalizadora en la cual debe integrarse Colombia si no quiere permanecer al margen de los procesos de internacionalización económica que se viven en el mundo desde hace ya más de treinta años.

Inicialmente se presentara la forma como estos países efectuaron sus procesos metodológicos y programáticos; con el fin de consolidar sus sistemas contables y compararlos con los sistema contables internacionales, para poder hacer un proceso más sencillo en términos de adopción, adaptación, armonización y convergencia, ya que de estas experiencias le pueden servir a países como Colombia para encontrar el camino más adecuado sin pasar por las dificultades que han tenido que pasar algunos países, igualmente se pretende con este trabajo lograr el respaldo de la comunidad contable nacional, para asegurar armonía y estabilidad en los procesos de aplicación de las IFRS.

Iniciaremos este trabajo relatando de una manera detallada y sencilla cada una de las experiencias, para lo cual aleccionaremos la experiencia de la República de la Argentina, debido a que es un país con una característica especial que se evidencia en su forma de organización político-administrativa la cual se establece mediante Estados Provinciales, donde las leyes favorecen la autonomía en el control de la profesión contable a Consejos locales (por distritos provinciales), lo que a lo largo de la historia contable de la Argentina, ha implicado diferencias al momento de establecer pautas en la valorización y revelación, en especial con el Consejo de la Ciudad Autónoma de Buenos Aires (CABA), que no es miembro de la Federación Argentina de Consejos Profesionales de Ciencias Empresariales (FACPCE) $y$ que tradicionalmente ha sido divergente y soberanamente independiente respecto a la FACPCE. Lo que provocó que en la Argentina, se presentara la necesidad de consensuar una armonización nacional, de tal forma que no existan diferencias dentro del propio país, para luego hacer frente a 
la armonización internacional, cabe anotar que en palabras del ex Presidente (Phielipp, 2001) de la FACPCE, manifestó que "ante esta realidad, se puede concluir que resulta muy difícil un proceso de armonización ${ }^{1 "}$. Pero esta realidad que ha sabido llevar este país, no ha sido impedimento para avanzar positivamente en este proceso de acercamiento a las NIIF, pues de los países de América del Sur es el primero ${ }^{2}$ en "homologar" sus normas locales bajo los criterios promovidos por el IASB.

En cuanto al caso particular de Brasil es preciso mencionar que los principales órganos profesionales de contabilidad son el Consejo Federal de Contabilidad (CFC) y el Instituto de Auditores Independientes de Brasil (IBRACON), han publicado conjuntamente una comparación de las normas contables brasileñas y las NIIF. Y sus primeros informes han determinado que el sistema contable brasilero ha estado marcado por una permanente mezcla entre la contabilidad financiera y el sistema fiscal del país. Este hecho es reconocido por diversos autores tales como (Nobes, 1992), (Lopez de Sá, 1996), (Callao, 1998), (Jarne \& Callao, 2001); (kKoliver, 2001); (Martins \& Lisboa, 2005) y (Katsumi, 2005) quienes en sus heterogéneas publicaciones han manifestado que la adopción estándares inexplorados y con una orientación exclusivamente hacia proveer información financiera, puede significar un obstáculo para las empresas nacionales brasileras.

Igualmente, es preciso mencionar, que de las seis organizaciones que convergen en el Brasil entorno a la contabilidad, existen cuatro que se preocupan en mayor grado por el desarrollo contable y financiero del país, ellas son: El Consejo Federal de Contabilidad (CFC) que emite las Normas Brasileñas de Contabilidad (NBC-T y NBC-P); Instituto de Auditores de Brasil (IBRACON) que emite pronunciamientos de auditoría y contabilidad, estos últimos bajo el nombre de Normas y Procedimientos de Contabilidad (NPC) y su logro más importante al respecto ha sido que la Comisión de Valores Mobiliarios (CVM) haya oficializado algunas de ellas; y cuyo alcance recae sobre las empresas que hacen oferta pública de sus acciones y emiten consideraciones contables específicas para este segmento de empresas (que son las mayores empresas del Brasil) y finalmente el Banco Central que como organismo vinculado al Ministerio de Hacienda tiene entre otros objetivos velar por la estabilidad y perfeccionar el sistema financiero nacional, para lo cual emite normas legales y resoluciones impositivas a instituciones financieras.

Por su parte, se puede decir que Bolivia estructuro un proyecto con el fin de contribuir a que la información financiera de las empresas que operan en Bolivia sea técnicamente fiable, objetiva, comparable, uniforme y transparente. El objetivo de dicho proyecto es que los profesionales miembros del Colegio de Auditores o Contadores Públicos de Bolivia (CAUB) apliquen normas contables y de auditoría acordes a la normativa internacional NIIF y NIA. Los resultados esperados son: 1) normas bolivianas armonizadas con las normas internacionales; 2) profesionales del ramo que conozcan el sistema contable boliviano y que tengan acceso a las normas bolivianas internacionales; y 3) procurar una mejora ostensible en la calidad de los servicios profesionales de auditoría buscando entre otros un proceso de mejoramiento continua a través de un adecuado sistema de certificación voluntario, un sistema de control de calidad y un centro de información permanente.

Las NIC habrán de orientar gradualmente el esquema que tendrá la información financiera en el país. Cabe anotar que actualmente un significativo número de estas NICs ya han sido aprobadas en Bolivia y se han estado adoptando gradualmente.

Mientras que en Chile se puede mencionar que fue el Colegio de Contadores de Chile A.G . quién en el año 2004, firmó un convenio con el Banco

1 Corresponde a algunos apartes del discurso pronunciado en Washington, en abril de 2001 en el seminario sobre implementación de normas de contabilidad y auditoría organizado por el BID. Tomado del Boletín №38 (2002), disponible en www.facpce.org.ar on-line consultado el 12.11.2009.

2 Los otros dos países de América del Sur que han armonizados son Perú y Uruguay, quienes han "adoptado" las NIIF de forma íntegra. Consultado en www.facpe.org.ar. On-line el día 12 de noviembre de 2009. 
Interamericano de Desarrollo (BID), en su calidad de Administrador del Fondo Multilateral de Inversiones (FOMIN), con el fin de Insertar a Chile en el ámbito internacional, aplicando criterios uniformes en la presentación de informes de carácter financierocontable, facilitando la integración comercial, siendo la Convergencia de Principios Contables nacionales a Normas Internacionales el principal componente. Dicho convenio señala que el plazo para la ejecución del Programa es de cuarenta y ocho meses, por lo tanto, la Comisión Técnica de Principios y Normas de Contabilidad ha preparado un plan de trabajo considerando que las nuevas normas de contabilidad, resultantes del Plan de Convergencia, serán emitidas a lo largo de dicho periodo, lo que se traduce en una fecha límite de implementación para el 01 de enero de 2009.

Costa Rica por su parte ha hecho un trabajo más paulatino el cuál inicia con la adopción de las Normas Internacionales de Contabilidad y es la Junta Directiva del Colegio de Contadores Públicos quien ha definido una clara política de adopción y armonización de las Normas Internacionales de Contabilidad, con el propósito de fomentar la transparencia y claridad en la forma de presentar los estados financieros de las empresas. Esta junta en la sesión ordinaria 18-99, del 21 de septiembre de 1.999 y mediante el acuerdo número 5.1.1. determino que las Normas Internacionales de Contabilidad, son formuladas y publicadas por el Comité de Normas Internacionales de Contabilidad, órgano del sector privado independiente, y que a su vez está integrado, entre otras entidades, por las asociaciones profesionales de contadores que son miembros de la Federación Internacional de Contadores, institución de la que el Colegio de Contadores Públicos de Costa Rica forma parte, siendo el objetivo de este Comité, al emitir tales normas, mejorar y armonizar las regulaciones contables, que permitan la más adecuada presentación de los estados financieros, dentro del contexto del interés público.

La República del Ecuador, decidió adoptar las normas internacionales de información financiera, y lo hizo mediante la resolución No.06.Q.ICI.004 emitida por el señor superintendente de compañías, el cual establecía que en el Ecuador, se había decidido adoptar dichas normas a partir del día primero de enero de 2009. Igualmente estableció que las NIIF fuesen de aplicación obligatoria por parte de las entidades sujetas a control y vigilancia de la superintendencia de compañías. En dicha resolución se derogaron, la resolución No.99.1.3.3.007 del 25 de agosto de 1999, y la resolución No.02.Q.ICI.002 del 18 de marzo de 2002, mediante las cuales se disponía que las normas ecuatorianas de contabilidad de la No.1 y hasta la 15 y las 18 a la 27 , respectivamente, sean de aplicación obligatoria por parte de las entidades sujetas al control y vigilancia de la superintendencia de Compañías. Cabe anotar que quienes establecieron las normas en la república ecuatoriana, lo hicieron enfocándose en tres conceptos fundamentales a saber: la relevancia, la confiabilidad y la comparabilidad.

Perú por su parte estableció un proceso de adopción de las Normas Internacionales de Contabilidad, con mayor rigurosidad, que muchos otros países y prueba de ello es que este país tiene una serie de organismos emisores de normas entre los cuales podemos mencionar al CONASEV: Organismo creado el 28 de mayo de 1968, y que inició funciones el 2 de junio de 1970 fue creado mediante el Decreto Ley № 18302. Se rige por su Ley Orgánica, Decreto Ley № 26126, del 30 de diciembre de 1992. Y tiene como funciones expedir la normatividad contable de las empresas que mantienen valores inscritos en la bolsa de valores, a los agentes de bolsa o intermediarios, la SBS: Regulada por Ley № 26702 Ley General del Sistema Financiero y del Sistema de Seguros y Orgánica de la Superintendencia de Banca y Seguros. Además, por Ley 27328, supervisa al Sistema Privado de Pensiones (SPP) y a las AFP. Es el organismo encargado de dictar normas para el registro de operaciones, elaboración, presentación y publicación de estados financieros, y el Consejo Normativo de Contabilidad: Por Ley, a través de los años, se ha regulado al sistema nacional de contabilidad en el país. Actualmente se encuentra en vigencia la Ley General del Sistema Nacional de Contabilidad, la cual establece: Su aplicabilidad a todas las entidades del sector público y al sector privado.

En la República Bolivariana de Venezuela, el proceso de aplicación de las NIC inicio a principios del 2004, donde la Federación de Colegios de Contadores Pú- 
blicos de Venezuela anunció en el mes de Marzo del 2004, que se iniciaría el proceso de adaptación a las nuevas normas internacionales de contabilidad (NIC's-IFRS), manifestando que dicho proceso podría demorar hasta el 2007 para establecerse en todo el espectro empresarial venezolano; tal decisión fue acordada por el directorio de la Federación de Colegios de Contadores Públicos de Venezuela (FCCPV) y la misma fue el resultado de un año de intenso trabajo interinstitucional entre el Comité Permanente de Principios de Contabilidad de la FCCPV y el Comité Normas Contables y Financieras del IVEF hasta esta fecha, al cual se le sumaron posteriormente otras instituciones como las Superintendencias de Seguros y de Bancos, la Comisión Nacional de Valores (CNV), la Bolsa de Valores de Caracas (BVC) y El Consejo Empresarial Venezolano de Auditoría (CEVA), entre otras importantes organizaciones públicas y privadas, y fue la Federación de Colegios de Contadores Públicos de Venezuela se promulgo el marco de adopción de las comúnmente conocidas NIIF, donde se aprobó su adopción, con dos fechas establecidas en: 31 de diciembre del 2008 o fecha de cierre posterior, para grandes entidades y 31 de diciembre del 2010 o fecha de cierre posterior, para las Pequeñas y Medianas Entidades (PyME),definidas en el Boletín de Aplicación BA VEN NIF 1 V0 de Noviembre, de 2008; a partir de las cuales los Principios de Contabilidad Generalmente aceptados en Venezuela se identificaran con las siglas VEN-NIIF y los Boletines de Aplicación como BA VEN-NIIF. Por lo tanto en Venezuela se utilizará la traducción oficial al español de las NIIF, emitidas por la fundación IASC. Se entiende por entidad, cualquier unidad identificable, que realice actividades económicas.

En razón a lo expuesto aquí, es que vamos a encontrar que cada experiencia es particular y única, $y$ que a pesar de que unos países, hacen el proceso de adopción, armonización o adaptación, a través de organismos de control y vigilancia, y otros lo hacen directamente mediante leyes estatales, la filosofía es la misma, y esta no otra que ingresar al mundo de los negocios internacionales, con igualdad de condiciones en cuanto al manejo de la información y presentación de la misma bajo un mismo lenguaje el cual sea entendible para todas las empresas y países con los cuales se tengan tratados comerciales.

\section{Principales experiencias y desarrollo del proceso en la República de la Argentina}

El caso de la República de la Argentina era hasta hace poco muy particular pues este país posee una situación que lo caracteriza al momento de afrontar un proceso de armonización contable. Esta característica se evidencia en su forma de organización político-administrativa que establece Estados Provinciales, donde las leyes favorecen la autonomía en el control de la profesión contable a Consejos locales (por distritos provinciales), lo que a lo largo de la historia contable de la Argentina, ha implicado diferencias al momento de establecer pautas en la valorización y revelación, en especial con el Consejo de la Ciudad Autónoma de Buenos Aires (CABA), que no es miembro de la Federación Argentina de Consejos Profesionales de Ciencias Empresariales (FACPCE) y que tradicionalmente ha sido divergente $\mathrm{y}$ soberanamente independiente respecto a la FACPCE. Lo que provoco que en la Argentina, se presentara la necesidad de consensuar una armonización nacional, de tal forma que no existan diferencias dentro del propio país, para luego hacer frente a la armonización internacional, cabe anotar que en palabras del ex Presidente (Phielipp, 2001) de la FACPCE, manifestó que "ante esta realidad, se puede concluir que resulta muy difícil un proceso de armonización ${ }^{3}$. . Pero esta realidad que ha sabido llevar este país, no ha sido impedimento para avanzar positivamente en este proceso de acercamiento a las NIIF, pues de los países de América del Sur es el primero 4 en "homologar" sus normas locales bajo los criterios promovidos por el IASB.

3 Corresponde a algunos apartes del discurso pronunciado en Washington, en abril de 2001 en el seminario sobre implementación de normas de contabilidad y auditoría organizado por el BID. Tomado del Boletín №38 (2002), disponible en www.facpce.org.ar on-line consultado el 12.11.2009.

4 Los otros dos países de América del Sur que han armonizados son Perú y Uruguay, quienes han "adoptado" las NIIF de forma íntegra. Consultado en www.facpe.org.ar. On-line el día 12 de noviembre de 2009. 
Durante los periodos comprendidos entre los años 2000 y 2002 la Federación Argentina de Consejos Profesionales en Ciencias Económicas (FACPCE) y en su caso los respectivos Consejos Provinciales y de la Capital, aprobaron una actualización de las normas vigentes para armonizarlas con las normas Internacionales de Contabilidad propuestas por el International Accounting Standards Committee (IASC).

Luego de un estudio y actualización de las normas contables de la República Argentina, la Federación Argentina de Consejos Profesionales de Ciencias Económicas (FACPCE) dio a conocer el cronograma que tendrán que tener en cuenta las empresas a fin de implementar las normas contables internacionales. A través de la Resolución técnica No. 26, la cual se emitió el día 20 de Marzo de 2009, y en la cual se establecieron los pasos y las acciones que las compañías deben comenzar a realizar de inmediato a fin de simplificar la adopción de las nuevas normas contables.

Por lo tanto y para dar cumplimiento a la Resolución técnica No. 26, emitida por la FACPCE, determino que a partir de los estados financieros que se presenten para el año 2009 , que cierren el ciclo contable de determinadas compañías, estas deberán dejar por escrito que ya están evaluando el impacto del nuevo marco normativo que deberá adoptarse en el año 2011.

Puntualmente, la nueva resolución emitida por la (FACPCE) establece que las normas internacionales de información financiera (NIIF) que deberán ser tenidas en cuenta a partir del año 2011, son aquellas emitidas por el Consejo de Normas Internacionales de Contabilidad (IASB) en la versión oficial en español, con sus respectivos análisis, comentarios y recomendaciones.

Igualmente la resolución hace la obligación explicita para aquellas compañías que cotizan sus operaciones en la Bolsa de valores, y determina que son estas empresas las que deben iniciar con el proceso, cabe anotar que la norma excluye taxativamente de la obligación a algunas de las compañías incluidas en el régimen de oferta pública de la Comisión Nacional de Valores (CNV), y ellas son:
Las empresas del panel de PyME que no están registradas en el régimen de oferta pública por su capital ni por sus obligaciones negociables, sino que operan bajo otras formas de financiación; Las restantes entidades bajo control de la CNV, tales como: Sociedades gerentes y depositarias de fondos comunes de inversión; Fondos comunes de inversión; Fiduciarios ordinarios públicos y fiduciarios financieros, inscritos en los registros que lleva la $\mathrm{CNV}$; Fideicomisos financieros autorizados a la oferta pública; Mercados de futuros y opciones; Entidades autorreguladas no bursátiles; Bolsas de comercio con o sin mercado de valores adherido; Cajas de valores; Entidades de compensación y liquidación; y Cámaras de compensación y liquidación de futuros y opciones, entre otras.

A su vez, la resolución técnica deja abierta la puerta para que todas las empresas que no cumplan con los requisitos que las obligan de manera puntual; puedan aplicar las NIIF de manera voluntaria y optativa, siempre a partir del año 2011; por otra parte, se establece que las empresas obligadas a implementar las normas contables internacionales sólo podrán dejar de hacerlo cuando ya no se encuentren incluidas en el régimen de oferta pública de la CNV.

También establece que de haber aplicado las normas de manera opcional, la compañía podrá dejar de aplicarlas siempre y cuando sustenten su decisión, de manera oportuna. Y complementariamente, la norma establece una serie de pautas a tener en cuenta por las entidades que presenten estados financieros consolidados.

Cabe anotar que si bien la Resolución técnica No. 26, no permite la adopción anticipada, para el primer grupo de empresas que se encuentran obligadas se deben comprometer a realizar algunas tareas extras a partir de los balances generales de cierre de operaciones que se presenten en el año 2009. Para ser más exactos los estados financieros anuales, correspondientes al ejercicio contable comprendido entre el 1 de enero al 31 de diciembre de 2009, las empresas deben realizar las siguientes actividades.

Identificar la norma que pone en vigencia las NIIF para la entidad y la fecha de cierre del ejercicio 
anual y del período intermedio en los que se prepararán los estados financieros de acuerdo con las NIIF, por primera vez.

Elaborar una declaración en donde se deje asentado que se están evaluando los efectos de la adopción de las normas contables internacionales.

En los casos en que la entidad haya concluido su análisis y tenga determinados los efectos del cambio, se deberán adjuntar las conciliaciones respectivas.

Como se puede apreciar el trabajo para los contadores públicos, aumentará aún más respecto a los estados financieros anuales correspondientes al ejercicio que se inicie a partir del 1 de enero de 2010 y que se cierra a 31 de diciembre del mismo año. Igualmente las compañías deberán adjuntar entre otras cosas lo siguiente:

a) Una conciliación entre el patrimonio neto determinado de acuerdo con las normas anteriores y el determinado de acuerdo con las NIIF.

b) Una conciliación entre el resultado integral total del ejercicio determinado de acuerdo con las NIIF y el importe equivalente a dicho resultado integral determinado a partir de los estados financieros de la entidad preparados de acuerdo con las normas contables anteriores.

Es preciso tener en cuenta que cuando los ajustes o reclasificaciones que se deban efectuar en el estado de flujo de efectivo, sean significativos, se deberá adjuntar una conciliación entre el efectivo y sus equivalentes y los totales de cada una de las causas de su variación determinados de acuerdo con las normas anteriores y los determinados de acuerdo con las NIIF.

Igualmente es preciso mencionar que actualmente los PCGA vigentes en la República de la Argentina se adecuan en sus aspectos más importantes a los principios internacionales, pero mantienen diferencias con los principios generalmente aceptados en los Estados Unidos (US GAPP).

\section{Principales experiencias en Brasil}

Dos de los principales órganos profesionales de contabilidad del Brasil a saber el Consejo Federal de Contabilidad (CFC) y el Instituto de Auditores Independientes de Brasil (IBRACON), han publicado conjuntamente una comparación de las normas contables brasileñas y las NIIF. Y en su informe han determinado que el sistema contable brasilero ha estado marcado por una permanente mezcla entre la contabilidad financiera y el sistema fiscal del país. Este hecho es reconocido por diversos autores tales como (Nobes, 1992), (Lopez de Sá, 1996), (Callao, 1998), (Jarne \& Callao, 2001); (Koliver, 2001); (Martins \& Lisboa, 2005) y (Katsumi, 2005) quienes en sus heterogéneas publicaciones han manifestado que la adopción estándares inexplorados y con una orientación exclusivamente hacia proveer información financiera, puede significar un obstáculo para las empresas nacionales brasileras.

Cabe anotar que en el Brasil convergen principalmente seis organizaciones entorno a la contabilidad, de las cuales existen cuatro que se preocupan en mayor grado por el desarrollo contable del país, ella son: El Consejo Federal de Contabilidad (CFC) que emite las Normas Brasileñas de Contabilidad (NBC-T y NBC-P); Instituto de Auditores de Brasil (IBRACON) que emite pronunciamientos de auditoría y contabilidad, estos últimos bajo el nombre de Normas y Procedimientos de Contabilidad (NPC) y su logro más importante al respecto ha sido que la Comisión de Valores Mobiliarios (CVM) haya oficializado algunas de ellas; y cuyo alcance recae sobre las empresas que hacen oferta pública de sus acciones y emiten consideraciones contables específicas para este segmento de empresas (que son las mayores empresas del Brasil) y finalmente el Banco Central que como organismo vinculado al Ministerio de Hacienda tiene entre otros objetivos velar por la estabilidad y perfeccionar el sistema financiero nacional, para lo cual emite normas legales y resoluciones impositivas a instituciones financieras.

Por lo tanto, el caso brasileño es muy parecido al caso argentino, en el sentido que no existe un único organismo vinculado en los temas contables y finan- 
cieros, y por lo tanto presenta una dificultad adicional, al efectuar un proceso de armonización frente a esa diversidad de normatividad contable interna.

Brasil al ser miembro del MERCOSUR obviamente participó de GIMCEA, y sin muchos antecedentes en la literatura sobre su rol en este Grupo, si se observa una coincidencia que se ubica en el año 1997. Recordemos que ese año es cuando se elevó la declaración desde GIMCEA acerca de la diversidad contable entre los cuatro países miembros y se proponía continuar el camino hacia la armonización internacional según normas del IASB. La coincidencia está en que ese mismo año, en diciembre, se promulga la NBC-T №11 "Normas de auditoría independiente de las demostraciones contables", la cual regula la actividad de auditoría a los estados financieros y donde se declara lo siguiente: "La auditoría de las demostraciones contables constituye el conjunto de procedimientos técnicos que tiene por objetivo la emisión de una opinión sobre la adecuación a los Principios Fundamentales de Contabilidad y las Normas Brasileñas de Contabilidad y, en lo que fuere pertinente, la legislación específica en la ausencia de disposiciones específicas, prevalecen las prácticas ya consagradas por la Profesión Contable, formalizadas o no por sus propios organismos". Es decir, aplica el abanico de consideraciones contables, por sobre si está normada una situación por los organismos de Brasil. Al respecto, Palacios \& Martínez (2005) lo ven como una alusión a las NIC, señalándolo como un apoyo a la convergencia internacional.

\section{Principales experiencias en Bolivia}

En el vecino país de Bolivia es el Consejo Técnico Nacional de Auditoria y Contabilidad, es el organismo encargado de adoptar decisiones y dictar las Normas de Contabilidad que se aplican en el país. Las principales normas contables que se utilizan actualmente en Bolivia son las siguientes.
NC 1: Principios de Contabilidad Generalmente Aceptados.

NC 2: Tratamiento contable de hechos posteriores al cierre del ejercicio.

NC 3: Estados financieros a moneda constante.

NC 4: Revalorización técnica de Activos Fijos.

NC 6: Tratamiento contable de las diferencias de cambio.

NC 7: Valuación de inversiones permanentes.

NC 8: Consolidación de Estados Financieros.

Bolivia estructuro un proyecto con el fin de contribuir a que la información financiera de las empresas que operan en Bolivia sea técnicamente fiable, objetiva, comparable, uniforme y transparente. El objetivo de dicho proyecto es que los profesionales miembros del Colegio de Auditores o Contadores Públicos de Bolivia (CAUB) 5 apliquen normas contables y de auditoría acordes a la normativa internacional NIIF y NIA. Los resultados esperados son: 1) normas bolivianas armonizadas con las normas internacionales; 2) profesionales del ramo que conozcan el sistema contable boliviano y que tengan acceso a las normas bolivianas internacionales; y 3) procurar una mejora ostensible en la calidad de los servicios profesionales de auditoría buscando entre otros un proceso de mejoramiento continua a través de un adecuado sistema de certificación voluntario, un sistema de control de calidad y un centro de información permanente.

Las NIC habrán de orientar gradualmente el esquema que tendrá la información financiera en el país. Cabe anotar que actualmente un significativo número de estas NICs ya han sido aprobadas en Bolivia y se han estado adoptando gradualmente.

Cabe anotar que las Normas Internacionales de Contabilidad (NIC) en Bolivia tienen como prioridad orientar a los profesionales contables en la preparación y presentación de los Estados Financieros de

5 El Colegio de Auditores o Contadores Públicos de Bolivia - CAUB, es una asociación civil de carácter profesional y gremial sin fines de lucro, de duración indefinida, Entidad que aglutina a los nueve Colegios Departamentales y a través de estos afilia a los siguientes profesionales: Contadores Públicos o Auditores y profesionales de las ciencias contables y financieras con título universitario a nivel de licenciatura, Contadores con título profesional a nivel técnico superior; empresas consultoras de contabilidad, auditoría y consultoría. Entre otros. Consultado en www.auditoresycontadoresdebolivia.org.bo, el día 14 de Noviembre de 2009. 
las empresas y se fusionan con los procedimientos relativos a la presentación de estados financieros. Estas normas y procedimientos no tienen fuerza jurídica obligatoria, pero se prevé que las partes interesadas lo adopten voluntariamente como parte de su quehacer contable.

Los profesionales contables Bolivianos han comprendido que el establecimiento de normas de contabilidad aceptadas mundialmente facilita las operaciones internacionales. Por lo tanto están convencidos que la armonización internacional de normas de contabilidad mejorará la comparación de la información contable. El desarrollo de ofertas globales o de ofertas internacionales, que se proponen colocar valores en más de una localidad, a fin de posibilitar proyectos importantes y lograr eficiencia financiera y la consecuente estandarización de la información que ellas demandan. El primer vestigio en esta armonización, la constituye sin duda alguna la información contable.

Entre los principales cambios que se han propuesto los profesionales contables en Bolivia, es que los principios de contabilidad, aparte de basarse en sólidos fundamentos, como serían los estándares nacionales $e$ internacionales, deben comprender reglas que alcancen entre otras cosas a: La formulación de manuales contables; los cuales deben contar con adecuados planes de cuenta y dinámica de los mismos, Además de establecer normas para la presentación de la información financiera claras y que contengan entre otros: Los formatos en que se presentan, los detalles de contenido (notas explicitarías); las cuales deberán contener las explicaciones de los cambios más importantes y periodos de presentación frecuente de la información contable y financiera.

Aunque como es bien sabido para los profesionales contables de Bolivia un modelo de contabilidad es una abstracción del valor verdadero de una firma, cuando las normas son bien conocidas y se aplican de manera uniforme, los inversionistas pueden interpretar correctamente la situación financiera de la firma. En esta lógica se debe resaltar que los principios contables y estándares de auditoría son salvaguardas necesarias para la confiabilidad de la información financiera y se ha convertido en el instrumento más importante para reducir la brecha entre el valor declarado y el valor percibido es quizás el mejor de los principios de contabilidad y las normas de auditoría.

Existe una enérgica motivación para que las propias empresas proporcionen información a posibles inversionistas a fin de reducir la variación en los cálculos del valor de la firma y reducir el costo de capital de la firma. Ya que aquellas firmas que pueden proveer información de mejor calidad y más confiable serán reconocidas en los mercados financieros internacionales. Sí las personas con acceso a información interna de una empresa pudieran comunicarla de manera fidedigna, ésta información será muy útil para los inversionistas y se reflejaría en el valor de las acciones y demás valores de una firma.

\section{Principales experiencias en Chile}

En Chile según lo manifestado por (Silva \& Garrido, 2006) quienes plantean que en el contexto del proceso de globalización y enmarcado en una política de "salir al mundo", en los últimos años chile ha firmado una serie de Tratados de Libre Comercio, con muchos países, es así como muchas empresas extranjeras han iniciado actividades en el territorio chileno, a través de empresas filiales. Hasta la fecha, para reportar a los inversionistas extranjeros y a la matriz de las filiales que están en un importante segmento del territorio geográfico chileno y para que puedan entender los informes que se les envían, ha sido necesario convertir los estados financieros preparados con la normativa chilena a la normativa internacional.

Debido a lo anterior, cada vez comenzó a tomar más fuerza la necesidad de tener un lenguaje común en contabilidad, por tal razón en el mes de noviembre de 1971, el Honorable Consejo General del Colegio de Contadores de Chile creó la Comisión de Principios y Normas de Contabilidad, cumpliendo con una resolución en tal sentido del Cuarto Congreso Nacional (celebrado en septiembre de 1970), 
de acuerdo con la atribución contenida en la letra "g" del Art. 13 de la Ley No 13.011, que lo obliga a "dictar normas relativas al ejercicio profesional6".

El 09 de enero de 1973, el Honorable Consejo General del Colegio de Contadores aprueba el Boletín Técnico № 1 , en el cual se enuncia y explican los elementos constituyentes de la "Teoría Básica de la Contabilidad" en la cual se fundamentan las normas contables. Siendo este organismo la única entidad de derecho privado que tiene la facultad para emitir normas que son de aplicación general en Chile.

El Colegio de Contadores de Chile A.G. ${ }^{7}$. En el año 2004, firmó un convenio con el Banco Interamericano de Desarrollo (BID), en su calidad de Administrador del Fondo Multilateral de Inversiones (FOMIN), con el fin de Insertar a Chile en el ámbito internacional, aplicando criterios uniformes en la presentación de informes de carácter financierocontable, facilitando la integración comercial, siendo la Convergencia de Principios Contables nacionales a Normas Internacionales el principal componente. Dicho convenio señala que el plazo para la ejecución del Programa es de cuarenta y ocho meses, por lo tanto, la Comisión Técnica de Principios y Normas de Contabilidad ha preparado un plan de trabajo considerando que las nuevas normas de contabilidad, resultantes del Plan de Convergencia, serán emitidas a lo largo de dicho periodo, lo que se traduce en una fecha límite de implementación para el 01 de enero de 2009.

A la fecha, aumenta el número de consultores, de profesionales que se desempeñan en las empresas auditoras y/o en el ámbito académico, que han analizado los Principios de Contabilidad Generalmente Aceptados (P.C.G.A) en Chile comparándola con las Normas Internacionales de Información Financiera, destacando que las diferencias existentes se pueden tipificar o agrupar, como sigue:
- Existen PCGA que difieren de las NIC-NIIF: Corrección Monetaria, Retasación Técnica del Activo Fijo, Deterioro de Activos, Amortización del Goodwill.

- Existen PCGA que han adoptado las normas establecidas en NIC-NIIF, a partir de cierta fecha solamente: Impuestos Diferidos, Combinación de Negocios.

- PCGA que han adoptado solo parcialmente las NIC-NIIF: Derivados, Costos por interés.

- Existen normas en las NIC-NIIF, que no están establecidas en los PCGA y que en nuestro país no se aplica: Información financiera por segmentos, Ganancia por acción.

- Aplicación de NIC-NIIF, para materias específicamente no normadas en los PCGA: Planes de beneficios por retiro, Negocios en conjunto. Diferencias como éstas se han presentado entre la normativa contable internacional y la de otros países que han adoptado, o adaptado las Normas Internacionales de Información Financiera.

\section{Principales experiencias en Costa Rica}

En Costa Rica el proceso inicia con la adopción de las Normas Internacionales de Contabilidad y es la Junta Directiva del Colegio de Contadores Públicos quien ha definido una clara política de adopción y armonización de las Normas Internacionales de Contabilidad, con el propósito de fomentar la transparencia y claridad en la forma de presentar los estados financieros de las empresas. Esta junta en la sesión ordinaria 18-99, del 21 de septiembre de 1999 y mediante el acuerdo número 5.1.1. determino que las Normas Internacionales de Contabilidad, son formuladas y publicadas por el Comité de Normas Internacionales de Contabilidad, órgano del sector privado independiente, y que a su vez está

Extractado del Boletín Técnico № 1, Colegio de Contadores de Chile A.G. consultado el 12 de noviembre de 2009.

El Colegio de Contadores de Chile, tiene su origen en el Registro Nacional de Contadores, que agrupó la profesión en el año de 1932 por medio de la Ley №5.102. Posteriormente en 1958 se creó por la Ley №13.011 el "Colegio de Contadores de Chile", para transformarse por imperio del D.L. N 3.621 de 1981 en el actual Colegio de Contadores de Chile A.G. Consultado en http://www.contach.cl/resena.php. el día 12 de Noviembre de 2009. 
integrado, entre otras entidades, por las asociaciones profesionales de contadores que son miembros de la Federación Internacional de Contadores, institución de la que el Colegio de Contadores Públicos de Costa Rica forma parte, siendo el objetivo de este Comité, al emitir tales normas, mejorar y armonizar las regulaciones contables, que permitan la más adecuada presentación de los estados financieros, dentro del contexto del interés público.

Igualmente estableció que siendo responsabilidad del Colegio de Contadores Públicos de Costa Rica, según lo establece el artículo 14 de la ley 1038 del 19 de agosto de 1947 y sus reformas, promover el progreso de la ciencia contable y cuidar del adelanto de la profesión en todos sus aspectos, que igualmente es obligación del profesional cuidar de la adecuada aplicación de los principios de contabilidad generalmente aceptados.

Por lo tanto la Junta Directiva del Colegio de Contadores Públicos ante la existencia de una tendencia evidente a la modernización e integración de la economía mundial, lo cual tiene efectos cruciales en los diferentes mercados mundiales, incluyendo Costa Rica. Donde se presenta un elemento importante de este proceso, que consiste en una mayor demanda, por parte de los diferentes agentes económicos de productos $\mathrm{y} / \mathrm{o}$ servicios que tengan también un carácter y uso generalizado. Esta tendencia de la economía actual, obliga a los profesionales de la Contaduría Pública de Costa Rica a responder de manera similar, a las exigencias cada vez mayores de los inversionistas nacionales y extranjeros. En consecuencia, la profesión en Costa Rica debe alinearse a los estándares que están utilizando la mayoría de los países en el mundo.

Las Normas Internacionales de Contabilidad conforman un compendio articulado y técnico de principios de contabilidad que están siendo utilizados, con singular aceptación, en un número importante de países, tanto desarrollados como en vías de desarrollo, localizados en distintos continentes del planeta. Cada vez, es mayor el número de países que adoptan tales normas contables, y existe la tendencia a utilizar normas de contabilidad, que sean de aplicación global. Es claro que la profesión, a escala mundial, busca crear herramientas técnicas que permitan reducir, en vez de ensanchar, las diferencias en la aplicación de principios de contabilidad en el mundo, por lo que consecuentemente, se corregirán las discrepancias en los sistemas de información y se establecerá un lenguaje común. Es interesante señalar que los resultados del "Seminario de Estandarización de las Normas Internacionales de Contabilidad y Auditoría", celebrado en Mayo de 1.998 en Costa Rica, indican que una mayoría de los Contadores Públicos participantes comparten similares objetivos de estandarización de las prácticas contables del país.

Cabe anotar que la Comisión de Normas de Contabilidad, en su sesión ordinaria número 10-99 del 13 de septiembre de 1999, aprobó recomendar la adopción de las Normas Internacionales de Contabilidad y solicito emitir los pronunciamientos relativos a principios de contabilidad, los que son de acatamiento obligatorio para los contadores públicos autorizados, según lo indica el artículo 56 del "Reglamento de la Profesión de Contador Público Autorizado", publicado en la Gaceta Número 100 del 25 de mayo de 1982.

Por lo tanto Costa Rica decidió adoptar las siguientes Normas Internacionales de Contabilidad, emitidas por el Comité de Normas Internacionales de Contabilidad, como principios de contabilidad generalmente aceptados por la comunidad contable del país, con las observaciones que se apuntan.

NIC 1 "Presentación de Estados Financieros"
NIC 2 "Existencias"
NIC 4 "Tratamiento Contable de la Depreciación"
NIC 7 "Estados de Flujo de Efectivo"
NIC 8 "Utilidad o Pérdida Neta del Ejercicio, Errores Sustanciales, y Cambios en las Políticas Contables"

NIC 10 "Contingencias y Hechos Ocurridos Después de la Fecha del Balance"

NIC 11 "Contratos de Construcción"

NIC 14 "Información Financiera por Segmentos"

NIC 16 "Propiedad, Planta y Equipo"

NIC 17 "Arrendamientos"

NIC 18 "Ingresos"

NIC 19 "Costo de Planes de Jubilación" 
NIC 20 "Tratamiento Contable de los Subsidios Gubernamentales y Revelaciones Referentes a la Asistencia Gubernamental"

NIC 21 "Efectos de las Variaciones en Tipos de Cambio de Moneda Extranjera"8

NIC 22 "Combinaciones de Negocios"9

NIC 23 "Costos de Financiamiento"

NIC 24 "Revelaciones sobre Entes Vinculados"

NIC 25 "Tratamiento Contable de las Inversiones"

NIC 26 "Tratamiento Contable y Presentación de Información sobre Planes de Prestaciones de Jubilación"

NIC 27 "Estados Financieros Consolidados Tratamiento Contable de las Inversiones en Subsidiarias" NIC 28 "Tratamiento Contable de las Inversiones en Compañías Asociadas"

NIC 30 "Revelaciones en los Estados Financieros de Bancos e Instituciones Financieras"

NIC 31 "Información Financiera sobre Participaciones en Asociaciones en Participación"10

NIC 32 "Instrumentos Financieros: Revelaciones y Presentación"

NIC 33 "Utilidades por Acción"

NIC 34 "Informes Financieros Intermedios"

NIC 35 "Operaciones Discontinuadas"

NIC 36 "Deterioro de Activos"

NIC 37 "Provisiones, Pasivos Contingentes y Activos Contingentes"

NIC 38 "Activos Intangibles"

Igualmente se determino dejar en estudio las Normas Internacionales de Contabilidad Números 12 "Impuesto a la Renta", y 39, "Instrumentos Financieros: Reconocimiento y Medición", por lo que cualquier referencia de estas dos normas en las aprobadas, no se considera de aplicación en Costa Rica, hasta tanto las mismas no sean aprobadas por el Colegio.
Las Normas Internacionales de Contabilidad adoptadas, utilizan terminología y conceptos que son apropiados para empresas o entidades que tienen como objetivo la generación de utilidades. Las empresas o entidades públicas que obtienen utilidades o no, u otras entidades privadas de carácter no lucrativo, utilizarán estas normas, adaptándolas a sus requerimientos técnicos y legales. Las Normas Internacionales de Contabilidad adoptadas mediante la presente resolución, podrían no coincidir con leyes vigentes o normas dictadas, dentro del campo de su competencia por entes reguladores, como la Superintendencia General de Entidades Financieras, la Superintendencia General de Valores o la Superintendencia General de Pensiones. Para cumplir con estas disposiciones específicas, los entes regulados deberán preparar Estados Financieros según la normativa establecida para ellos. No obstante, dicha presentación será solamente para esos efectos regulatorios y no deberá interpretarse que constituye una presentación según las Normas Internacionales de Contabilidad adoptadas.

\section{Principales experiencias y desarrollo del proceso en la República del Ecuador}

El país hermano del Ecuador, decidió adoptar las normas internacionales de información financiera, y lo hizo mediante la resolución No.06.Q.ICI.004 emitida por el señor superintendente de compañías, el cual establecía que la República del Ecuador, había decidido adoptar dichas normas a partir del día primero de enero de 2009.

Igualmente estableció que las NIIF sean de aplicación obligatoria por parte de las entidades sujetas a control y vigilancia de la superintendencia de compañías. En dicha resolución se derogaron, la resolu-

8 Las referencias efectuadas por esta Norma, a las Normas Internacionales de Contabilidad números, 39, "Instrumentos Financieros: Reconocimiento y Medición", en su párrafo 14; y 12, "Impuesto a la Renta", en su párrafo 41, no se consideran aplicables para Costa Rica, hasta tanto no se produzca un estudio y aprobación de esas Normas Internacionales de Contabilidad.

9 Nota: Las referencias efectuadas en esta norma, a la Norma Internacional de Contabilidad Número 12, en los párrafos 68 y 69, no se consideran aplicables en Costa Rica, hasta tanto no se produzca el estudio y aprobación de esta norma.

10 El párrafo 13 debe leerse así: "Un activo controlado conjuntamente es aquel activo contribuido o adquirido por parte de los inversionistas, para el propósito del negocio conjunto. Los activos incurridos". En el párrafo 17 debe sustituirse la palabra "riesgos" por "registros". 
ción No.,99.1.3.3.007 del 25 de agosto de 1999, y la resolución No.02.Q.ICI.002 del 18 de marzo de 2002, mediante las cuales se disponía que las normas ecuatorianas de contabilidad de la No.1 y hasta la 15 y las 18 a la 27 , respectivamente, sean de aplicación obligatoria por parte de las entidades sujetas al control y vigilancia de la superintendencia de Compañías.

Cabe anotar que quienes establecieron las normas en la república ecuatoriana, lo hicieron enfocándose en tres conceptos fundamentales a saber: la relevancia, la confiabilidad y la comparabilidad. Con la entrada en vigencia de las NIIF a partir del primero de enero de 2009, las compañías requieren obligatoriamente cumplir con las siguientes disposiciones:

a) En la preparación de los estados financieros deben involucrarse todas las NIIF, siguiendo de manera rigurosa cada uno de los pasos que permitan formular el balance general inicial.

b) En la república del ecuador se deben reconocer todos los activos y pasivos que son requeridos por las NIIF.

c) No se podrán reconocer ni activos ni mucho menos pasivos que las NIIF no reconozcan.

d) Es necesario que los profesionales contables reclasifiquen los activos, pasivos y el patrimonio clasificados o identificados de acuerdo con otros principios o normas que en la actualidad no concuerden con las NIIF.

e) Aplicar cada una de las NIIF en la medición de todos los activos y pasivos registrados.

Al igual que la mayoría de países, la república del ecuador, estableció unos pasos fundamentales para la aplicación de las NIIF en el territorio ecuatoriano y estos pasos son:

1. Conocimiento previo de las operaciones del ente económico: Debido a que es importante conocer de manera previa el objeto social de la entidad, involucrando sus políticas contables aplicadas en la preparación de los estados financieros.

2. Efectuar un diagnostico preliminar: Una vez hayan sido identificadas las operaciones, se debe diagnosticar la viabilidad de aplicación de las NIIF observando las principales reglas que rigen la implementación por primera vez.

3. Debe efectuarse una capacitación y actualización permanente: El personal involucrado en las operaciones contables y financieras de la entidad, deberá encontrarse perfectamente capacitado en el conocimiento y aplicación de las NIIF.

4. Debe efectuarse evaluaciones: Una vez se hayan cumplido todos los procesos anteriores, se debe realizar una evaluación de los componentes de los estados financieros, que deberán ser clasificados por cuentas o grupos de cuentas, con el fin de depurar la información constante en ellos.

5. La conversión inicial de los estados financieros: Una vez reconocidos razonablemente los activos, pasivos y patrimonio, el ente económico estará en capacidad técnica de realizar la conversión de los estados financieros en la fecha de transición.

6. Requerimientos Mínimos y Básicos: Las Contadores, administradores y demás colaboradores de la organización tendrán que aceptar el cambio en las cifras del balance y demás estados financieros; así como el cambio de los procesos para generar información financiera; de igual forma el personal deberá cambiar su forma de pensamiento conceptual para operar y generar información con aplicación de las NIIF y de igual manera deben cambiar los sistemas de información. En conclusión es un cambio radical y general de los agentes como de los medios.

7. Implementación: Mediante los procesos indicados, se obtendrán los primeros estados financieros de forma comparativa: ejercicios económicos de los años 2008 y 2009 bajo NIIF.

En cuanto al análisis e interpretación de los estados financieros con aplicación de las NIIF y los posibles impactos tributarios, se ha determinado que para el pago del impuesto de renta en concordancia con las 
leyes vigentes de la materia, siempre seguirá existiendo la conciliación tributaria, proceso que depura tanto los ingresos gravables como los gastos y costos no deducibles; por consiguiente, el interés fiscal no estará ajeno a los cambios contables que experimentará el país en materia de las NIIF.

\section{Principales experiencias en el Perú}

Perú en uno de los países que estructuralmente ha establecido un proceso de adopción de las Normas Internacionales de Contabilidad, con mayor rigurosidad y prueba de ello es que este país tiene una serie de organismos emisores de normas entre los cuales podemos citar los siguientes:

CONASEV ${ }^{11}$ : Organismo creado el 28 de mayo de 1968, inició funciones el 2 de junio de 1970 fue creado mediante el Decreto Ley № 18302 . Se rige por su Ley Orgánica, Decreto Ley № 26126, del 30 de diciembre de 1992. Éste tiene como funciones expedir la normatividad contable de las empresas que mantienen valores inscritos en la bolsa de valores, a los agentes de bolsa o intermediarios.

La SBS ${ }^{12}$ : Regulada por Ley № 26702 Ley General del Sistema Financiero y del Sistema de Seguros y Orgánica de la Superintendencia de Banca y Seguros. Además, por Ley 27328, supervisa al Sistema Privado de Pensiones (SPP) y a las AFP. Es el organismo encargado de dictar normas para el registro de operaciones, elaboración, presentación y publicación de estados financieros.

\section{El CONSEJO NORMATIVO DE CONTABILI-}

DAD: Por Ley, a través de los años, se ha regu- lado al sistema nacional de contabilidad en el país. Actualmente se encuentra en vigencia la Ley General del Sistema Nacional de Contabilidad, la cual establece: Su aplicabilidad a todas las entidades del sector público y al sector privado.

Este consejo define al Sistema Nacional de Contabilidad como el conjunto de políticas, principios, normas y procedimientos contables que deben aplicar los sectores público y privado. Y tiene como función: Establecer como objetivo del Sistema Nacional de Contabilidad armonizar y homogenizar la contabilidad en los sectores público y privado mediante la aprobación de la normatividad contable. Igualmente es el encargado de estudiar, analizar y opinar sobre las propuestas de normas relativas a la contabilidad de los sectores públicos y privado; Emitir resoluciones dictando y aprobando las normas de contabilidad para las entidades del sector privado; y absolver consultas en materia de su competencia.

\section{Antecedentes de la aplicación de las NIIF en Perú}

Diversos Congresos Nacionales de Contadores Públicos del Perú adoptaron acuerdos para la aplicación de las Normas Internacionales de Contabilidad (NIC) según Resoluciones: $\mathrm{N}^{\circ} 39$ del X Congreso de Lima en 1986 (NICS 1 a la 13); N 12 del XI Congreso del Cusco en 1988 (NICS 14 a la 23) y; $\mathrm{N}^{\circ} 1$ del XII Congreso de Cajamarca en 1990 (NICS 24 a la 29). El Consejo Normativo de Contabilidad, el 18 de abril de 1994, mediante Resolución $N^{\circ} 005-$ 94-EF/93.01 oficializó la aplicación de las Normas Internacionales de Contabilidad adoptados en los Congresos antes mencionados; precisando que los estados financieros deben ser preparados cumpliendo las mencionadas normas.

11 La Comisión Nacional Supervisora de Empresas y Valores del Perú - CONASEV - es un organismo público descentralizado adscrito al Ministerio de Economía y Finanzas. Tiene como finalidad promover el mercado de valores, velar por el adecuado manejo de las empresas y normar la contabilidad de las mismas. Asimismo tiene como finalidad velar por el cumplimiento de la Ley del Mercado de Valores. Tiene como sede la ciudad de Lima. En http://es.wikipedia.org/wiki/Comisiion_Nacional_Supervisora_de_ Empresas_y_Valores_del_Perú. Consultada el 17 de noviembre de 2009.

12 La Superintendencia de Banca, Seguros y AFP es el organismo encargado de la regulación y supervisión de los Sistemas Financiero, de Seguros y, a partir del 25 de julio del 2000, del Sistema Privado de Pensiones (SPP) (Ley 27328) Su objetivo primordial es preservar los intereses de los depositantes, de los asegurados y de los afiliados al SPP. La SBS es una institución de derecho público cuya autonomía funcional está reconocida por la Constitución Política del Perú. Sus objetivos, funciones y atribuciones están establecidos en la Ley General del Sistema Financiero y del Sistema de Seguros y Orgánica de la Superintendencia de Banca, Seguros y AFP (Ley 26702). En http://es.wikipedia.org/wiki/Comisiion_Nacional_Supervisora_de_Empresas_y_Valores_del_Perú. Consultada el 17 de noviembre de 2009. 
El reconocimiento de las NIC no sólo se dio en el campo profesional, sino también en el campo legal, pues en 1997 la Ley de Sociedades № 26887, en su artículo $223^{\circ}$, estableció la obligatoriedad de que los estados financieros se preparen y presenten de conformidad con las normas legales y los "Principios de Contabilidad Generalmente Aceptados".

La Resolución N 013-98-EF/93.01 del Consejo Normativo de Contabilidad precisó que los Principios de Contabilidad Generalmente Aceptados a que se refiere la Ley General de Sociedades comprende sustancialmente, a las Normas Internacionales de Contabilidad (NICS), oficializadas, y las normas establecidas por Organismos de Supervisión y Control para las entidades de su área siempre que se encuentren dentro del Marco Teórico en que se apoyan las Normas Internacionales de Contabilidad.

La misma resolución $\mathrm{N}^{\circ}$ 013-98-EF/93.01 precisó que por excepción y en aquellas circunstancias que determinados procedimientos operativos contables no estén establecidos en una Norma Internacional de Contabilidad, supletoriamente, se podrá emplear los Principios de Contabilidad aplicados en los Estados Unidos de América (hoy USGAAP).

\section{Proceso de la aprobación de las NIIF en el Perú}

Las normas oficializadas por el CNC al 31 de diciembre de 2006, son las NIC vigentes de la 1 a la 41, las NIIF de la 1 a la 6 y las interpretaciones vigentes de la 1 a la 33. Estas normas incluyen las NIC revisadas incluidas en el Proyecto de Mejoras emprendido por el IASB (1, 2, 8,10, 16, 17, 21, 24, 28, 29, 31, 32, 33, 39 y 40) vigentes en el Perú a partir del 1 de enero de 2006 (Internacionalmente el 1 de enero de 2005). A la fecha no han sido aprobadas las NIIF 7 y 8 , con vigencia internacional a partir del 1 de enero de 2007, así como las CINIIF.

La Resolución CNC № 008 - 97 EF/93.01 del 23 /01 / 1997, ha precisado las obligaciones que debe cumplir el contador público cuando actúe profesionalmente en función dependiente o independiente (debe aplicar los PCGA, las NICs (ahora NIIFs), las leyes pertinentes y el Código de Ética Profesional.
El incumplimiento de dichas obligaciones determina que el contador público incurra en "culpa inexcusable” previsto en el Art. 1321ํel Código Civil.

En el siguiente cuadro se relacionan, las normas internacionales, en su versión inicial y en la versión actual, la resolución que las creo y la fecha en que entraron en vigencia, para poder hacer un comparativo en trabajos posteriores con las normas de los países objeto de investigación, y establecer cuáles han sido las principales modificaciones y punto de encuentro entre normas.

\section{Principales experiencias en la República Bolivariana de Venezuela}

De conformidad con el Boletín de Aplicación, BA VEN NIF 0 V2 de Noviembre del 2008, de la Federación de Colegios de Contadores Públicos de Venezuela se promulgo el marco de adopción de las comúnmente conocidas NIIF, donde se aprobó su adopción, con dos fechas establecidas en: 31 de diciembre del 2008 o fecha de cierre posterior, para grandes entidades y 31 de diciembre del 2010 o fecha de cierre posterior, para las Pequeñas y $\mathrm{Me}$ dianas Entidades (PyME),definidas en el Boletín de Aplicación BA VEN NIF 1 V0 de Noviembre, de 2008; a partir de las cuales los Principios de Contabilidad Generalmente aceptados en Venezuela se identificaran con las siglas VEN-NIIF y los Boletines de Aplicación como BA VEN-NIIF. Por lo tanto en Venezuela se utilizará la traducción oficial al español de las NIIF, emitidas por la fundación IASC. Se entiende por entidad, cualquier unidad identificable, que realice actividades económicas.

\section{La aplicación de las NIC en Venezuela}

El proceso de aplicación de las NIC inicio a principios del 2004, donde la Federación de Colegios de Contadores Públicos de Venezuela anunció en el mes de Marzo del 2004, que se iniciaría el proceso de adaptación a las nuevas normas internacionales de contabilidad (NIC's-IFRS), manifestando que dicho proceso podría demorar hasta el 2007 para establecerse en todo el espectro empresarial venezolano. 
Tabla 1. Normas internacionales de información financiera oficializadas en el Perú13

\begin{tabular}{|c|c|c|c|c|}
\hline $\begin{array}{l}\mathrm{NIC} \\
\mathrm{N}^{\circ}\end{array}$ & TÍTULO & Versión & $\begin{array}{l}\text { Resolución de } \\
\text { CNC N }\end{array}$ & $\begin{array}{l}\text { Vigencia } \\
\text { a partir de }\end{array}$ \\
\hline & $\begin{array}{l}\text { Prefacio a los Pronunciamientos sobre Normas Internacionales } \\
\text { de Contabilidad y el Marco Conceptual para la Preparación y Pre- } \\
\text { sentación de los Estados Financieros }\end{array}$ & & 005-94-EF/93.01 & $\begin{array}{l}1 \text { de enero de } \\
1994\end{array}$ \\
\hline 1 & Presentación de Estados Financieros & $\begin{array}{l}\text { Modificada en } \\
\text { dic. } 2003\end{array}$ & 034-2005-EF/93.01 & $\begin{array}{l}1 \text { de enero de } \\
2006\end{array}$ \\
\hline 2 & Existencias & $\begin{array}{l}\text { Modificada en } \\
\text { dic. } 2003\end{array}$ & 034-2005-EF/93.01 & $\begin{array}{l}1 \text { de enero de } \\
2006\end{array}$ \\
\hline 7 & Estado de Flujos de Efectivo & $\begin{array}{l}\text { Modificada en } \\
1992\end{array}$ & 005-94-EF/93.01 & $\begin{array}{l}1 \text { de enero de } \\
1994\end{array}$ \\
\hline 8 & $\begin{array}{l}\text { Políticas Contables, cambios en estimaciones contables y erro- } \\
\text { res }\end{array}$ & $\begin{array}{l}\text { Modificada en } \\
\text { dic. } 2003\end{array}$ & 034-2005-EF/93.01 & $\begin{array}{l}1 \text { de enero de } \\
2006\end{array}$ \\
\hline 10 & Sucesos Posteriores a la Fecha del Balance General & $\begin{array}{l}\text { Modificada en } \\
\text { dic. } 2003\end{array}$ & 034-2005-EF/93.01 & $\begin{array}{l}1 \text { de enero de } \\
2006\end{array}$ \\
\hline 11 & Contratos de Construcción & $\begin{array}{l}\text { Modificada en } \\
1993\end{array}$ & 007-96-EF/93.01 & $\begin{array}{l}1 \text { de enero de } \\
1996\end{array}$ \\
\hline 12 & Impuesto a la Renta & $\begin{array}{l}\text { Modificada en } \\
2000\end{array}$ & 028-2003-EF/93.01 & $\begin{array}{l}1 \text { de enero de } \\
2003\end{array}$ \\
\hline 16 & Inmuebles, Maquinaria y Equipo & $\begin{array}{l}\text { Modificada en } \\
\text { dic. } 2003\end{array}$ & 034-2005-EF/93.01 & $\begin{array}{l}1 \text { de enero de } \\
2006\end{array}$ \\
\hline 17 & Arrendamientos & $\begin{array}{l}\text { Modificada en } \\
\text { dic. } 2003\end{array}$ & 034-2005-EF/93.01 & $\begin{array}{l}1 \text { de enero de } \\
2006\end{array}$ \\
\hline 18 & Ingresos & $\begin{array}{l}\text { Modificado en } \\
1993\end{array}$ & 007-96-EF/93.01 & $\begin{array}{l}1 \text { de enero de } \\
1996\end{array}$ \\
\hline 19 & Beneficios a los Trabajadores & $\begin{array}{l}\text { Modificada en } \\
2000\end{array}$ & 028-2003-EF/93.01 & $\begin{array}{l}1 \text { de enero de } \\
2003\end{array}$ \\
\hline 20 & $\begin{array}{l}\text { Tratamiento Contable de los Subsidios Gubernamentales y Reve- } \\
\text { laciones Referentes a la Asistencia Gubernamental }\end{array}$ & $\begin{array}{l}\text { Reordenada } \\
\text { en } 1994\end{array}$ & 005-94-EF/93.01 & $\begin{array}{l}1 \text { de enero de } \\
1994\end{array}$ \\
\hline 21 & $\begin{array}{l}\text { Efectos de las Variaciones en los Tipos de Cambio de Monedas } \\
\text { Extranjeras }\end{array}$ & $\begin{array}{l}\text { Modificada en } \\
2003\end{array}$ & 038-2005-EF/93.01 & $\begin{array}{l}1 \text { de enero de } \\
2007\end{array}$ \\
\hline 23 & Costos de Financiamiento & $\begin{array}{l}\text { Modificada en } \\
1993\end{array}$ & 007-96-EF/93.01 & $\begin{array}{l}1 \text { de enero de } \\
1996\end{array}$ \\
\hline 24 & Revelaciones Sobre Entes Vinculados & $\begin{array}{l}\text { Modificada en } \\
\text { dic. } 2003\end{array}$ & 034-2005-EF/93.01 & $\begin{array}{l}1 \text { de enero de } \\
2006\end{array}$ \\
\hline 26 & $\begin{array}{l}\text { Tratamiento Contable y Presentación de Información sobre Pla- } \\
\text { nes de Prestaciones de Jubilación }\end{array}$ & $\begin{array}{l}\text { Reordenada } \\
\text { en } 1994\end{array}$ & 005-94-EF/93.01 & $\begin{array}{l}1 \text { de enero de } \\
1994\end{array}$ \\
\hline 27 & Estados Financieros Consolidados e individuales & $\begin{array}{l}\text { Modificada en } \\
\text { dic. } 2003\end{array}$ & 034-2005-EF/93.01 & $\begin{array}{l}1 \text { de enero de } \\
2006\end{array}$ \\
\hline 28 & Inversiones en Asociadas & $\begin{array}{l}\text { Modificada en } \\
\text { dic. } 2003\end{array}$ & 034-2005-EF/93.01 & $\begin{array}{l}1 \text { de enero de } \\
2006\end{array}$ \\
\hline
\end{tabular}

13 Fuente: http://www.perucontable.com. Fecha de Actualización: 12 de Noviembre de 2009. 


\begin{tabular}{|c|c|c|c|c|}
\hline $\begin{array}{l}\mathrm{NIC} \\
\mathrm{N}^{\circ}\end{array}$ & TÍTULO & Versión & $\begin{array}{c}\text { Resolución de } \\
\text { CNC N }\end{array}$ & $\begin{array}{l}\text { Vigencia } \\
\text { a partir de }\end{array}$ \\
\hline 29 & Información Financiera en Economías Hiperinflacionarias & $\begin{array}{l}\text { Reordenada } \\
\text { en } 1994\end{array}$ & 005-94-EF/93.01 & $\begin{array}{l}1 \text { de enero de } \\
1994\end{array}$ \\
\hline 31 & Participaciones en Asociaciones en Participación & $\begin{array}{l}\text { Modificada en } \\
\text { dic. } 2003\end{array}$ & 034-2005-EF/93.01 & $\begin{array}{l}1 \text { de enero de } \\
2006\end{array}$ \\
\hline 32 & Instrumentos Financieros: Presentación & $\begin{array}{l}\text { Modificada } \\
2006\end{array}$ & 040-2008-EF/94 & $\begin{array}{l}1 \text { de enero de } \\
2009\end{array}$ \\
\hline 33 & Utilidades por Acción & $\begin{array}{l}\text { Modificada en } \\
\text { dic. } 2003\end{array}$ & 034-2005-EF/93.01 & $\begin{array}{l}1 \text { de enero de } \\
2006\end{array}$ \\
\hline 34 & Informes Financieros Intermedios & ORIGINAL & 014-98-EF/93.01 & $\begin{array}{l}1 \text { de enero de } \\
1999\end{array}$ \\
\hline 36 & Deterioro del Valor de los Activos & $\begin{array}{l}\text { Modificada en } \\
\text { marzo } 2004\end{array}$ & 034-2005-EF/93.01 & $\begin{array}{l}1 \text { de enero de } \\
2006\end{array}$ \\
\hline 37 & Provisiones, Pasivos Contingentes y Activos Contingentes & ORIGINAL & 019-00-EF/93.01 & $\begin{array}{l}1 \text { de enero de } \\
2000\end{array}$ \\
\hline 38 & Activos Intangibles & $\begin{array}{l}\text { Modificada } \\
\text { marzo } 2004\end{array}$ & 034-2005-EF/93.01 & $\begin{array}{l}1 \text { de enero de } \\
2006\end{array}$ \\
\hline 39 & Instrumentos Financieros: Reconocimiento y Medición & $\begin{array}{l}\text { Modificada } \\
2003\end{array}$ & 034-2005-EF/93.01 & $\begin{array}{l}1 \text { de enero de } \\
2006\end{array}$ \\
\hline 40 & Inversiones Inmobiliarias & $\begin{array}{l}\text { Modificada en } \\
\text { dic. } 2003\end{array}$ & 034-2005-EF/93.01 & $\begin{array}{l}1 \text { de enero de } \\
2006\end{array}$ \\
\hline 41 & Agricultura & ORIGINAL & 024-2001-EF/93.01 & $\begin{array}{l}1 \text { de enero de } \\
2003\end{array}$ \\
\hline
\end{tabular}

Tal decisión fue acordada por el directorio de la Federación de Colegios de Contadores Públicos de Venezuela (FCCPV) y la misma fue el resultado de un año de intenso trabajo interinstitucional entre el Comité Permanente de Principios de Contabilidad de la FCCPV y el Comité Normas Contables y Financieras del IVEF hasta esta fecha, al cual se le sumaron posteriormente otras instituciones como las Superintendencias de Seguros y de Bancos, la Comisión Nacional de Valores (CNV), la Bolsa de Valores de Caracas (BVC) y El Consejo Empresarial Venezolano de Auditoría (CEVA), entre otras importantes organizaciones públicas y privadas.

Venezuela actualmente se encuentra en ese proceso de adaptación de las 41 Normas Internacionales de Contabilidad (NIC's-IFRS), con sus respectivas 31 interpretaciones como Principios de Contabilidad de Aceptación General (PCAG).

Igualmente se estableció que para instituir y lograr todos los objetivos propuestos se propuso la realiza- ción de un cronograma detallado que describa cada una de las actividades a ser realizadas para actualizar al gremio contable, igualmente se crearon distintos comités los cuales tienen como tarea fundamental el establecimiento, y el inicio de la adaptación de los pensum universitarios al cambio de legislación, $e$ informar convenientemente a los ejecutivos de finanzas de las empresas (iniciando con aquellas que cotizan en los mercados de capitales) y avanzar a los restantes sectores empresariales, incluyendo aquellos que tienen legislaciones que impactan en la presentación de sus estados financieros, como son la banca y las empresas de seguros, concluyendo con el de la pequeña y mediana empresa industrial (PyME).

Por otra parte la Comisión Nacional de Valores (CNV), ente regulador de Mercados de Capital Venezolano, a través de la Resolución 157-2004, del 02 de Diciembre de 2004, publicada en la Gaceta Oficial de la República Bolivariana de Venezuela, Nro. 38.085, de fecha 13 de Diciembre de 2004, 
modificada según Resolución 68-2005, de fecha 08 de Junio de 2005, publicada en la Gaceta Oficial Nro.38.218, de fecha 29 de Junio de 2005, resolvió que las empresas que hagan Oferta Pública de Valores en los términos de la Ley de Mercados de Capitales, deberán preparar y presentar sus Estados Financieros ajustados a las Normas Internacionales de Información Financiera (NIIF), de manera obligatoria a partir de los periodos contables que se inicien el 01 de Enero de 2005. En este sentido, tal preparación y presentación deberá ser efectuada mediante las Normas Internacionales de Información Financiera (NIIF), vigentes al 01 de Enero de 2005.

Es preciso mencionar que La república Bolivariana de Venezuela ve la adopción de las Normas Internacionales de Contabilidad como un proceso que ayudara a mejorar la percepción internacional de Venezuela y las empresas venezolanas como receptoras de inversiones, al hacer mucho más sencilla para la revisión de inversionistas extranjeros la presentación de los estados financieros de las empresas Venezolanas. Con todo ello, se espera que el cambio se constituya en una ventaja comparativa que mejore la posición de dichas empresas en el complejo mundo de la globalización económica actual.

\section{Impacto internacional}

En fin, la adopción de estas normas permitirá a Venezuela crear las condiciones para un mercado de capitales integrado y eficaz aumentando la comparabilidad de las cuentas en el mercado para la competencia y la circulación de capitales y evitar así la costosa tarea de tener que traducir las mismas cuentas a diferentes normas internacionales.

Es importante enfatizar, que la implementación de las Normas Internacionales de Información Financiera (NIIF), es con el propósito de mejorar la competitividad y la transparencia y facilitará el libre movimiento de capitales y un funcionamiento eficaz de los mercados de capitales a nivel mundial.

Ahora bien, es claro que dichas Normas son de obligatorio cumplimiento para aquellas sociedades que cotizan en los mercados de capitales y las pequeñas y medianas empresas (PyME). Partiendo de su realidad contable, deberán ajustarse a la adopción de las Normas Internacionales de Contabilidad, ya que en Venezuela la gran mayoría de las PyME llevan contabilidad y presentan Estados Financieros al solo con el propósito de cumplir los requisitos legales establecidos en las Leyes Tributarias, tanto nacionales como municipales, es decir, que los Estados Financieros no están destinados a terceros que toman sus decisiones económicas sobre dicha base.

A nivel mundial existe la siguiente interrogante, es conveniente que las PyME, apliquen las mismas Normas de Información Financiera requeridas a las empresas que cotizan en las Bolsas de Valores de cada país?, indudablemente que no, porque le generaría costos administrativos inútiles, imponiendo procedimientos contables complejos para elaborar Estados Financieros que nadie lee; por lo tanto, es un grave error exigirle a las PyME y Asociaciones Cooperativas, normas contables que no pueden cumplir, es obligarlas a incurrir en mayores costos administrativos que afectaría la competitividad de las mismas. En muchos casos, estos mayores costos, no podrán ser asumidos y las PyME tendrán que optar entre no cumplir las Normas Contables o cerrar.

Un ejemplo claro, es lo que sucede a las Asociaciones Cooperativas Venezolanas, que les es exigido para efectos de inscribirse en el Registro Nacional de Contratistas (RNC), entre otros requisitos, que sus Estados Financieros, estén auditados por Contadores Públicos en ejercicio independiente, contraviniendo Normas Legales, ya que la Ley Especial de Asociaciones Cooperativas, no establece la obligatoriedad a las mismas de que sus Estados Financieros estén Auditados por Contadores Públicos independientes, la gran mayoría de estas PYMES, optan por no inscribirse en virtud de lo costoso que es realizar una Auditoría de sus Estados Financieros y mucho menos, si están en período pre-operativo.

En conclusión, es importante diferenciar entre las Empresas Mercantiles que hagan Oferta Pública de Valores en los términos de la Ley de Mercados de Capitales y las pequeñas y medianas empresas (PyME) y Asociaciones Cooperativas, porque estas 
últimas, no podrán nunca competir en igualdad de condiciones.

\section{Conclusiones y aprendizajes}

Es preciso anotar que con la agilidad y celeridad, que han venido adoptando las Normas Internacionales de Contabilidad y las Normas Internacionales de Información Financiera algunos países del mundo, estas se convertirán en el corto plazo en el marco contable de mayor uso y de amplia difusión en todos los países del mundo, y los usuarios de esta información exigirán que la misma sea preparada y presentada bajo dichas normas.

Pero la principal conclusión a la que se pudo llegar con esta investigación, es que todavia hay mucho trabajo por hacer, en países como Venezuela, Perú, Brasil y Costa Rica, pues a pesar de haber sido abanderados de la adopción, adaptación o armonización en unos casos particulares, muchas de la empresas de estos países aún no aplican dichas normas internacionales, $y$ aducen la resistencia a dicho proceso, a que por abastecer solo el mercado local en sus países, no ven la necesidad de aplicarlas, pues no creen en que en un futuro próximo, puedan a llegar a ser proveedores o mantener negociaciones con empresas del exterior, además prefieren vender sus empresas a compañías multinacionales, que cambiar sus sistemas de información contable y financiero según lo han manifestado algunos empresarios venezolanos especialmente.

Debe presumirse que los estados financieros preparados bajo la metodología propuesta por las NIC y presentada acorde a las NIIF, necesariamente expresaran de manera más razonada, la realidad económica y financiera de las empresas o de cualquier entidad que aplique dichas normas, buscando con ello garantizar la transparencia y la idoneidad de las cifras que sustentan dichos estados financieros.

Cabe anotar que la razonabilidad y transparencia de los estados financieros presentados sobre la base de las NIIF, se confirma en razón a que involucran varios términos que deben ser de aplicación permanente y estos son el Valor Justo, el Valor Presente, el Valor Razonable, y el Deterioro, entre otros.
En Latinoamérica, en especial en los países que convergen en Suramérica, y entre ellos Bolivia, Ecuador y Venezuela, especialmente este último, los empresarios deberán negociar con el gobierno, el manejo de las relaciones internacionales, pues de ello dependerá tanto en el presente como en el futuro, que las empresas venezolanas sigan siendo vistas por los inversionistas como, receptoras estratégicas de inversión extranjera, pues de seguir dicho gobierno con las medidas que ha tomado recientemente de efectuar compras hostiles de empresas, el mundo de los negocios internacionales se encargara de aislar a cualquier empresa de la República Bolivariana de Venezuela, puesto que dicho gobierno no que ofrece garantías, ni condiciones justas para dichos inversionistas, además que se está menoscabando el respeto por la libertad de empresa que debe imperar en un país bien gobernado.

Colombia, deberá guardar coherencia y celeridad en la aplicación de dichas normas en especial en aquellas empresas que cotizan en la bolsa de valores, pues de ello dependerá que se sigan efectuando tratados de libre comercio bilaterales o multilaterales, y la búsqueda de nuevos destinos de las exportaciones colombianas, pues es preciso que las empresas exportadoras de bienes y servicios de Colombia diversifiquen el destino de sus exportaciones y no sigan dependiendo de mercados internacionales, donde sus gobiernos confunden los tratados comerciales, con los asuntos políticos.

Los países que hayan adoptado o que estén en proceso de adopción de las Normas Internacionales de Contabilidad y de las Normas Internacionales de Presentación de Información Financiera, deberán revisar constantemente sus sistemas de información contable, de manera que los mantengan actualizados y conforme a las necesidades de información de un mundo que día a día se globaliza cada vez más, de manera que puedan efectuar los ajustes que sean necesarios en reciprocidad con la interpretación y aplicación jurídica de cada una de las normas adoptadas.

Se deben constituir procesos de capacitación y de asesoría permanente en cada uno de los países que hayan adoptado las NIC y las NIIF, al igual que 
deben constituir organismos colegiados que se encarguen de revisar y proponer los ajustes que estén en proceso y que hayan sido promulgados por los organismos internacionales de regulación contable reconocidos.

Finalmente para aquellos países que aún no han adoptado, adaptado, armonizado o que no hayan efectuado procesos de convergencia hacia la normatividad contable internacional, deben tomar las medidas que consideren necesarias para no quedarse rezagados de este proceso globalizador, pues de ello puede depende que sus empresas que realizan operaciones de comercio exterior, puedan seguir operando normalmente, pues como es bien sabido actualmente se están firmando tratados comerciales, con países Europeos, y estos por excelencia exigen que se hable un lenguaje contable común.

\section{Referencias}

Callao, S. (1998) Peculiaridades del analisis internacional. Manual de Contabilidad Internacional. Madrid: Piramide.

Cano, A. Las normas internacionales en la contabilidad y la entrada en vigencia de la ley 1314 de 2009 en el contexto contable colombiano" en Observatorio de la Economía Latinoamericana, No 121, 2009. Texto completo en http://www. eumed.net/cursecon/ecolat/co/.

Cano, A. (2009) Principales antecedentes históricos de las normas internacionales de contabilidad. Partida Doble, 24-40.

Cano, A. (2003) Crisis Estructural de la Sociedad en la Era de la Enseñanza. México D.F.: Vera Humanitas.

Franco, R. (2009) Avances de las Normas Internacionales en Colombia. Lumina, 15-35.
Jarne, J., \& Callao, S. (2001). "Sinópsis de las características contables de otros países". Del monográfico Manual de la contabilidad internacional. Madrid: Pirámide.

Katsumi, J. (2005). Contabilidade internacional. Sao Paulo.: Editora Atlas.

Koliver, O. (2001). "A interação, a haronização e a regulamentação da profissão contábil em um mundo globalizado: panorama das dificultades. Revista Brasileira de Contabilidade, No 131, 71-83

Lopez de Sá, A (1996). Teoria general del conocimiento contable. Zaragosa: Editores I.C.A.C.

Mantilla, S. (2001) Normas Internacionales de Contabilidad y su adecuacion al sistema contable nacional. Revista Legis del Contador , 33-45.

Martins, E., \& Lisboa, P. (2005). Ensaio sobre cultura e diversidade contábil. Revista Brasileira de Contabilidade, No152, 51-67.

Mattessich, R. (2001.). Hitos de la investigación en contabilidad moderna. Revista Legis del Contador. Bogotá, Colombia pp, 9-44.

Mueller, G. (1999). Contabilidad una perspectiva internacional. México: McGraw-Hill.

Mueller, G. (1965). La dimensión del problema de la contabilidad internacional. International Governamental Accounting Research, 18-45.

Nobes, C. (1992). International classification of financial reporting. Londres: Routledge.

Palacios, M., \& Martinez, I. (2005). El proceso de armonización contable en Latinoamérica: camino hacia las normas internacionales. Revista de Contabilidad y Finanzas No39, Universidad de São Paulo, 103-117.

Phielipp, E. (2001). Discurso pronunciado en Washington, en abril de 2001 en el seminario sobre implementación de normas de contabilidad y auditoría organizado por el BID. Washington: Informe de BID

Silva, P. \& Garrido, S. (2006). The convergence to International Standards of Financial Information in Chile. CAPIV REVIEW Vol. 4, 9,19. 